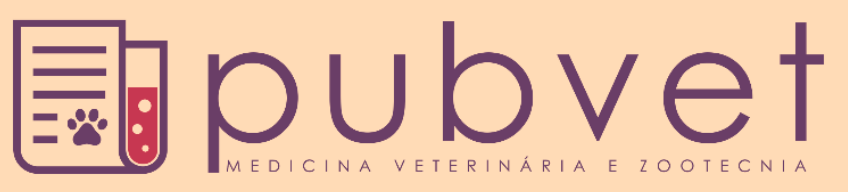

https://doi.org/10.31533/pubvet.v16n02a1040.1-8

\title{
Fistulação e canulação ruminal em bovinos: Revisão
}

\author{
Bruno Cristiano Begnini1*, Wesley Antunes Meireles ${ }^{20}$ \\ ${ }^{1}$ Acadêmico do Instituto Federal Catarinense - Campus Concórdia, Departamento de Medicina Veterinária, Concórdia - SC Brasil. \\ ${ }^{2}$ Professor do Instituto Federal catarinense - Campus Concórdia, Departamento de Medicina Veterinária, Concórdia - SC Brasil. \\ *Autor para correspondencia, E-mail: bruno-begnini@hotmail.com
}

\begin{abstract}
Resumo. A fistulação e canulação do rúmen em bovinos é uma técnica que possui grande importância nos estudos de nutrição animal. Com a implantação de cânulas, é possível avaliar o metabolismo e a fisiologia do pré-estômago, pesquisar a degradabilidade de alimentos e forragens in situ, além de serem importantes no processo de transfaunação que consiste na transferência de microbiota ruminal de um animal saudável para um doente. A fistulação do rúmen e a implantação da cânula são realizadas mediante intervenção cirúrgica, que variam conforme o tipo de cânula utilizada. Além disso, a fistulação pode ser realizada em um ou dois estágios operatórios, com diferentes técnicas cirúrgicas descritas na literatura. Complicações pós-operatórias e implicações éticas vem sendo relatadas no presente trabalho, além da importância de estudos realizados com a microbiologia ruminal, principalmente avaliando-se as interações entre os microorganismos e hospedeiros. Conclui-se que a técnica de canulação em bovinos, bem realizada cirurgicamente com menor sofrimento animal, sendo certificado pelo Comitês de Ética na Utilização de Animais, são importantes para pesquisas na área de nutrição animal e emergências na clínica de ruminantes.
\end{abstract}

Palavras-chave: Metabolismo, nutrição, transfaunação

\section{Ruminal fistulation and cannulation in cattle: Review}

Abstract. Rumen fistulation and cannulation in cattle is a technique that has great importance in animal nutrition studies. With the implantation of cannulas, it is possible to assess the metabolism and physiology of the pre-stomach, research the degradability of food and forage in situ, in addition to being important in the transfaunation process, which consists in the transfer of ruminal microbiota from a healthy animal to a sick. Rumen fistulation and cannula implantation are performed through surgical intervention, which vary according to the type of cannula used. In addition, fistulation can be performed in one or two operative stages, with different surgical techniques described in the literature. Postoperative complications and ethical implications have been reported in this work, in addition to the importance of studies carried out with ruminal microbiology, mainly by evaluating the interactions between microorganisms and hosts. It is concluded that the cannulation technique in cattle, surgically well performed with less animal suffering and certified by the Animal Use Ethics Committee, are important for research in the field of animal nutrition and emergencies in the ruminant clinic.

Keywords: Metabolism, nutrition, transfaunation

\section{Introdução}

O conceito de fistulação é um procedimento cirúrgico, caracterizado pela exteriorização de determinada porção do trato digestório do animal, com aberturas feitas desde a pele até a região do órgão a ser exteriorizada. A canulação, por sua vez, é a inserção de um tubo, de diferentes materiais, calibres e formas, aberto em ambas as extremidades, destinado a ser introduzido no corpo (Laflin \& Gnad, 2008). 
A prática de canulação ruminal foi documentada pela primeira vez por Schalk \& Amadon (1928). Possui grande importância nos estudos de nutrição animal, tornando possível avaliar o metabolismo e a fisiologia do pré-estômago com maior facilidade (Duffield et al., 2004; Grovum, 1989; Thyfault et al., 1975). Nos animais fistulados, também se pode pesquisar a degradabilidade in situ (Muniz et al., 2008; Santra \& Karim, 2002), além da realização da transfaunação, que consiste na transfusão de microbiota ruminal de uma animal saudável para o rúmen de um animal doente em diversas patologias (DePeters \& George, 2014). Pelas técnicas de canulação e estudos utilizando técnicas de biologia molecular, vem sendo catalogados novas espécies de microrganismos (Piknová et al., 2006) e avaliações da diversidade de fungos e bactérias no rúmen bovino (Fouts et al., 2012).

Diferentes técnicas cirúrgicas para a realização do procedimento já foram descritas na literatura (Atasoy \& Tass, 2003; Cabrera et al., 1996; Godwin \& Chaffey, 1988; Horigane et al., 1989; Mogha \& Bhargava, 1979).

Existe grande debate nos dias de hoje sobre a necessidade de se ter e produzir animais canulados, serão abordadas, portando, além da própria técnica, as vantagens e se há prejuízos no seu bem-estar e produção. A proposta desse trabalho é descrever uma revisão bibliográfica, abordada a técnica cirúrgica, a importância científica e novas descobertas microbiológicas do rúmen graças à fistulação de bovinos.

\section{Técnica operatória}

A fistulação consiste em procedimento cirúrgico realizado sob anestesia, caracterizado pela exteriorização de determinada porção do trato digestório do animal, com aberturas feitas desde a pele até a região do órgão a ser exteriorizada. Após abertura e perfeita cicatrização do local, é implantado uma cânula, que pode ser de material rígido ou maleável, com o objetivo de manter o orifício vedado e permitir acesso ao interior do órgão. O procedimento de fistulação de animais é descrito na literatura científica desde o século XIX, conforme "Fisiologia Digestiva y Nutrición de Los Ruminantes" (Church, 1974).

Para a realização da técnica os animais devem estar em jejum alimentar e hídrico, alguns autores citam 24 horas para ambos (Komarek, 1981), outros de 36 e 12 horas, respectivamente (Muzzi et al., 2009), os animais são mantidos em posição quadrupedal, de preferência em tronco de contenção, com acesso à região da fossa paralombar esquerda, realiza-se tricotomia da linha média dorsal até a base do úbere. O animal deve ser sedado e anestesiado e o campo deve ser esterilizado e mantido estéril com a utilização de pano de campo fenestrado. A incisão deve ser feita de forma circular, de acordo com o tamanho da cânula a ser utilizada, a pele incisada deve ser então dissecada e removida, formando uma falha circunferencial na pele (Figura 1), os músculos oblíquo externo, oblíquo interno e transverso do abdome devem ser divulsionados e afastados no sentido de suas fibras, permitindo o acesso ao peritônio que deve ser incisado com o auxílio de uma tesoura.

Após a abertura da cavidade uma porção dorsal do rúmen deve ser apreendida e tracionada expondo parte de sua parede, a porção exposta deve ser suturada ao peritônio e parte da pele, para que promova adequada justaposição entre rúmen e pele (Figura 2), sendo necessário que as suturas fiquem bem próximas umas das outras (Muzzi et al., 2009).

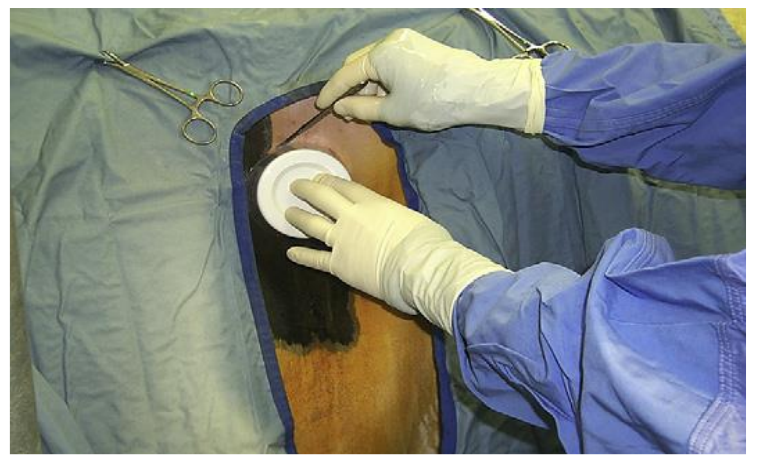

Figura 1. Modelo utilizado para demarcar a área a ser incisada. O modelo usado para marcar a área da pele a ser excisada deve ser de aproximadamente 0,05 menor que o diâmetro do anel interno da cânula. Fonte: Adaptado de Laflin \& Gnad (2008). 
Logo após a parede do rúmen deve ser incisada, a cerca de $0,5 \mathrm{~cm}$ de distância dos pontos e da borda da pele, promovendo a retirada de um retalho circular da parede do rúmen, a hemorragia deve ser sempre controlada pelo pinçamento e ligadura dos grandes vasos (Muzzi et al., 2009). Em seguida, as paredes do rúmen, envolvidas na incisão, deverão ser suturadas com padrões de eversão para fixá-las à pele (igura 3).

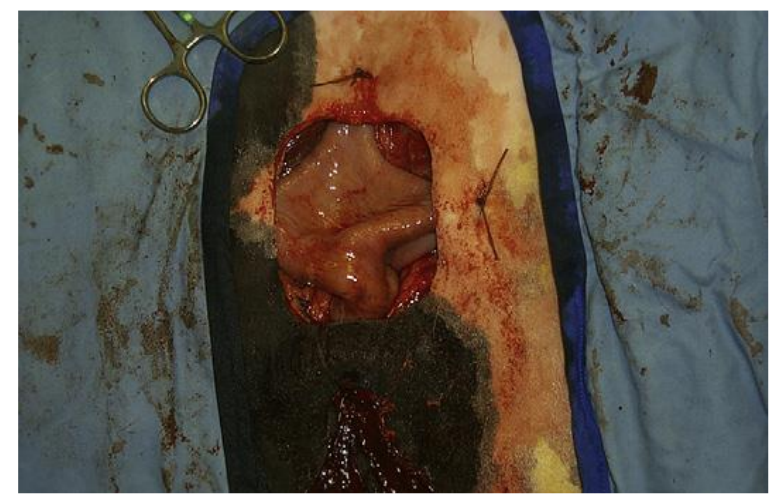

Figura 2. Suturas de suporte colocadas para estabilizar o rúmen. Fonte: Adaptado de Laflin \& Gnad (2008).

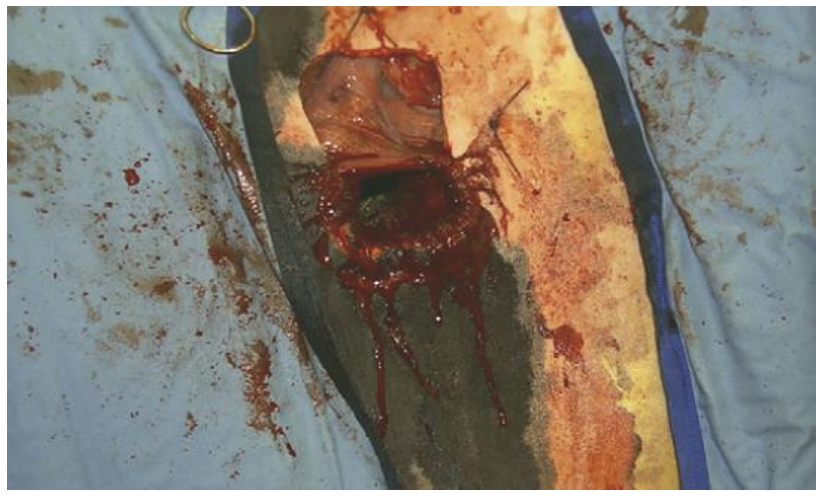

Figura 3. Detalhe do padrão de sutura de eversão utilizado para fixar o rúmen à pele na técnica de canulação.

A implantação da cânula (flange) ocorre logo após a síntese da ferida cirúrgica. Se a mesma for de material flexível, deve ser mantida em água aquecida para que se torne mais maleável e facilite a fixação no lúmen ruminal (Figura 4a). A aba interna deve ser posicionada fixamente à parede do rúmen, enquanto a aba externa deve ficar justaposta à pele (Figura $4 \mathrm{~b})$ e o tubo central ocupará o espaço criado pela fístula (Laflin \& Gnad, 2008).
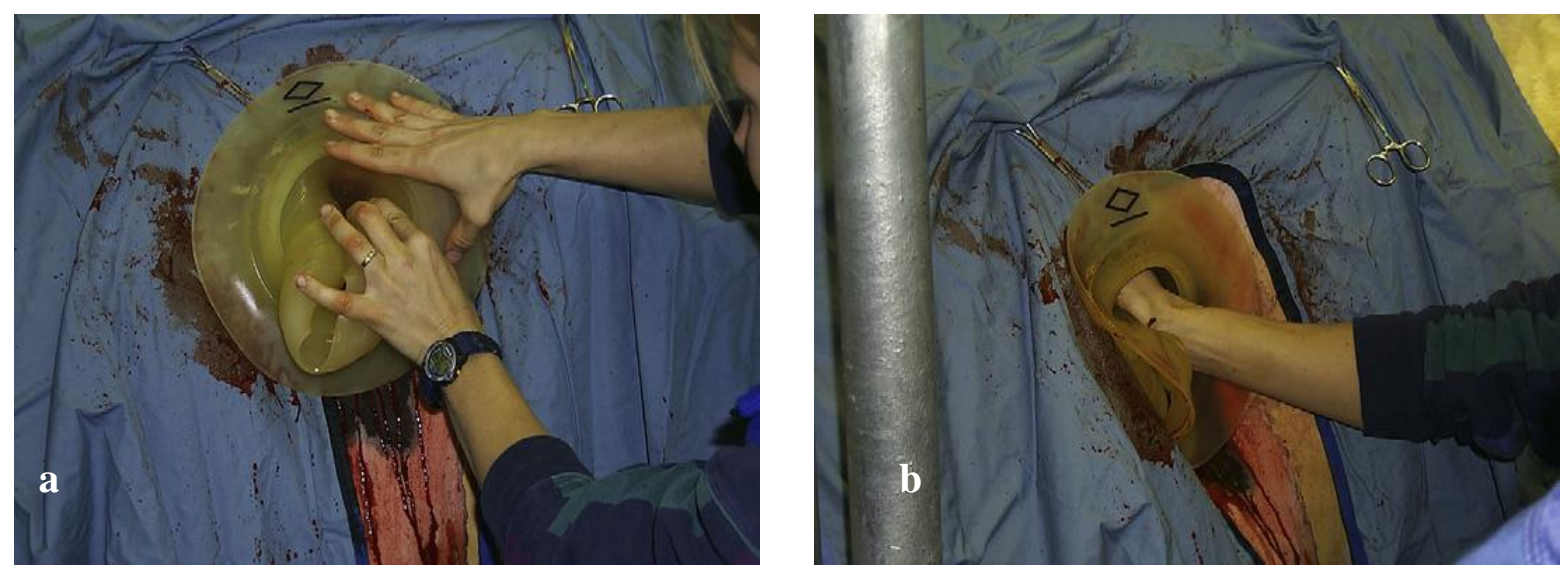

Figura 4. Flange interno sendo empurrado através do centro da cânula no lúmen do rúmen (a), sendo que uma vez invertido, o flange interno fixa a cânula ao rúmen (b). Adaptado de Laflin \& Gnad (2008)

No pós-operatório deve ser utilizada antibioticoterapia preventiva a base de oxitetraciclina $(20 \mathrm{mg} / \mathrm{kg})$ e anti-inflamatório, especificamente flunixina meglumina $(1,5 \mathrm{mg} / \mathrm{kg})$, por sete dias. Além de cuidados locais, limpeza e uso de cicatrizantes tópicos e as suturas de nylon devem ser retiradas após 14 dias ou após a completa cicatrização (Muzzi et al., 2009).

\section{Bem-estar e implicações éticas}

De acordo com Hungate (1966) e Church (1974), os animais fistulados adequadamente apresentam comportamento fisiológico normal, sem incômodo ou dor, não havendo prejuízo no consumo e digestibilidade do alimento, produção leiteira, reprodução e longevidade do animal. Porém, algumas complicações podem ocorrer após a implantação de cânulas permanentes, como peritonite e vazamento de conteúdo ruminal. Que pode levar o animal à um quadro de desidratação e desnutrição (Grovum, 1989).

A canulação deve ser feita de forma que vede perfeitamente o entorno da cânula, evitando que líquido ruminal extravase, formando lesões de pele, odor desagradável e evitando o aparecimento de miíases no período experimental (Muzzi et al., 2009). 
Várias entidades ligadas ao bem-estar animal consideram a prática de canulação como uma prática desnecessária, cruel, insensível e barbara, causando dor nos animais (Henderson, 2021). Como a técnica cirúrgica envolve sofrimento animal, necessita-se a submissão de projetos ao Comitê de Ética na Utilização de Animais para experimentos, caso aprovado, da certificação para realizar os procedimentos (BRASIL, 2008) em instituições de ensino superior.

\section{Justificativa da canulação em bovinos}

A técnica de fistulação de animais é imprescindível nos estudos de fisiologia, microbiologia e metabolismo ruminal, tornando possível obter conhecimento detalhado do processo digestivo e a avaliação de dietas, além de determinar parâmetros físicos e químicos envolvidos na digestão com exatidão, como a taxa de passagem de alimentos, $\mathrm{pH}$, nitrogênio amoniacal, ácidos graxos voláteis e o desenvolvimento de estratégias para mitigação do metano entérico. A canulação ainda permite a obtenção de amostras para estudos de micro-organismos do rúmen, como bactérias e fungos celulolíticos importantes nos estudos de diversas áreas (Arcuri et al., 2011).

Essas avaliações proporcionam informações fundamentais para o desenvolvimento de estratégias de alimentação mais eficazes para os bovinos e menos agressivas ao ambiente, a partir do melhor aproveitamento dos nutrientes e redução das excreções, como o metano, um gás tóxico liberado para o ambiente. Com base na técnica, produtos que melhorem a digestibilidade já estão sendo considerados, para serem utilizados em períodos de pastagens muito secas (Arcuri et al., 2011).

As pesquisas com animais fistulados de estratégias para a prevenção e tratamento de doenças que podem até mesmo levar a morte, como o timpanismo ruminal, têm contribuído de maneira muito importante para preservação da saúde e bem-estar da espécie (Santos, 2011).

Escolas de veterinária, hospitais veterinários e operações de criação de bovinos costumam manter um animal saudável fistulado como doador de microbiota. Os veterinários puxam manualmente o conteúdo do sistema ruminal de animais saudáveis (cerca de cinco litros) para ajudar a repovoar a fauna no rúmen de animais doentes. Esse processo é chamado de transfaunação ou transfusão de microbiota. Trabalhos anteriores indicaram que a transfaunação ajudou a corrigir indigestões causadas por doenças, correções cirúrgicas de abomaso deslocado e ingestão de plantas tóxicas (DePeters \& George, 2014).

\section{Microbiologia do rúmen}

O rúmen é considerado um ecossistema único e diverso, povoado por micro-organismos: bactérias, arqueas, fungos, protozoários e vírus (Siqueira \& Caviglioni, 2021). Nesse ecossistema, as bactérias constituem de 60 a 90\% da biomassa microbiana com cerca de 200 espécies distintas (Kozloski, 2011). $\mathrm{O}$ processo digestivo nesses animais é um sistema dinâmico que envolve a entrada de alimentos no rúmen e a saída de líquidos, partículas, microrganismos e resíduos não degradados para o omaso e abomaso (Pereira et al., 2002). Durante o processo evolutivo, desenvolveram a capacidade de aproveitar de forma eficiente os carboidratos estruturais como fonte energética e compostos nitrogenados nãoproteicos como fonte de proteína (Fonty et al., 1995; Hobson \& Stewart, 2012).

Seundo Withers (1992), os alimentos que chegam ao rúmen são constituintes de estruturas moleculares complexas e de alto peso molecular, indisponíveis às células bacterianas ruminais. Para atender as necessidades nutricionais bacterianas, estas estruturas são degradadas extracelularmente até porções monoméricas, passíveis de entrarem na célula e serem metabolizadas.

Os microrganismos ruminais que degradam as partículas de alimento podem ser funcionalmente divididos em: bactérias livres e associadas ao fluído ruminal; bactérias fracamente associadas as partículas; e bactérias fortemente aderidas as partículas de alimento (McAllister et al., 1994).

\section{As bactérias ruminais}

Para que a produtividade e a saúde dos ruminantes sejam mantidas, as bactérias ruminais são indispensáveis (Welkie et al., 2010). As bactérias são os seres presentes no líquido ruminal em maior número, e também são as que desempenham maior papel. São de suma importância no processo de fermentação e na degradação da lignina, celulose, hemicelulose, como também a proteína, o amido e o óleo contido nos alimentos. Conforme Nagaraja et al. (2012), a simbiose entre as bactérias e entre outros 
microrganismos promove a formação de ácidos graxos voláteis e a proteína microbiana ruminal. $\mathrm{O}$ número exato de espécies de bactérias ruminais ainda é desconhecido, devido a enorme variedade e a complexidade destes microrganismos. No entanto, já foram isoladas mais de 400 espécies oriundas do trato digestório de animais distintos (Krause \& Russell, 1996).

A classificação das bactérias comumente usada pelos pesquisadores é fundamentada no tipo de substrato em que os microrganismos agem e nos produtos finais da fermentação. São denominadas como fermentadoras de carboidratos estruturais (hemicelulolíticas), fermentadoras de carboidratos nãoestruturais, sendo estas as amilolíticas e pectinolíticas, e também metanogênicas, proteolíticas, lipolíticas e láticas (Arcuri et al., 2011).

\section{As arqueas ou metágenos ruminais}

Arqueas são organismos procariontes, estritamente anaeróbicos, morfologicamente semelhantes às bactérias, mas genética e bioquimicamente distintas, possuindo características que podem ser encontradas em eucariontes ou em bactérias, sendo os únicos microrganismos presentes no rúmen capazes de produzir o gás metano, que viabiliza o funcionamento do rúmen por servir como o principal dreno de hidrogênio (Mosoni et al., 2011).

As arqueas são microrganismos conhecidos por habitar ambientes considerados extremos, como aqueles ricos em sais e com temperaturas elevadas, entretanto, existem espécies que vivem em ambientes moderados (Siqueira \& Caviglioni, 2021). As arqueas são os principais organismos produtores de metano no rúmen e atualmente, há cerca 120 espécies identificadas. Os metanogênicos não são capazes de degradar moléculas complexas como a glicose e por isso dependem que outros organismos ruminais forneçam substratos para a metanogênese, relação conhecida como transferência de hidrogênio interespecífica. A produção de metano no rúmen é uma via comum da fermentação e faz com que o hidrogênio produzido pelas bactérias e protozoários seja utilizado pelas arqueas na redução do dióxido de carbono na produção desse composto orgânico, mantendo assim um nível mais baixo de hidrogênio ruminal. A produção de metano leva a perda de 2 a $12 \%$ de energia em ruminantes, que gera prejuízos econômicos e ambientais relacionados com o aquecimento global. Dessa forma, estratégia para mitigação da produção de metano em ruminantes tem sido bastante estudadas (Hook et al., 2010; Martin et al., 2010).

\section{Os protozoários ruminais}

Os protozoários desempenham funções bioquímicas e fisiológicas de grande importância para os ruminantes, principalmente no metabolismo de nutrientes (Coalho et al., 2003). Os protozoários realizam o engolfamento das bactérias a fim de utilizar os aminoácidos e ácidos nucleicos presentes como nutrientes (Kozloski, 2011). Alguns protozoários apresentam características celulolíticas, no entanto os substratos mais utilizados são o amido e os açúcares, pois são rapidamente fermentáveis e armazenados em amilopectina ou amido protozoário. A capacidade tamponante também é uma característica relevante dos protozoários, uma vez que as bactérias não tem disponibilidade de grandes quantidades de substratos rapidamente fermentáveis (Williams, 1986). O quimiotactismo por açucares, também é uma particularidade dos protozoários (Arcuri et al., 2011).

Segundo Dehority (2003), o grupo holotríquia adere-se a parede do retículo e desta forma migra até o rúmen, posteriormente a ingestão da dieta. Assim ocorre uma seleção de protozoários, em que os microrganismos maiores ficam reclusos no compartimento ruminal, o que proporciona a estes seres sobreviver neste ambiente, pois o tempo de geração é bastante longo (Hungate, 1966).

Algumas espécies de protozoários são encontradas nas primeiras seis semanas de vida no préestômago dos ruminantes, sendo que a colonização destes microrganismos varia conforme a dieta disponibilizada (Arcuri et al., 2011).

A saliva é responsável pela fonte de protozoários nos ruminantes, pois estes microrganismos migram pelo contato direto com animais faunados (Ivan et al., 2000).

O número e espécie de protozoários presentes no rúmen dos animais apresenta variação em relação ao período do dia, ingestão de alimento e água, características da dieta e produção salivar (Arcuri et al., 2011). 


\section{Fungos ruminais}

Os fungos anaeróbios do rúmen têm indicado que esses microrganismos desenvolvem importante papel na digestão e no ecossistema do trato digestório de ruminantes, podendo constituir até $8 \%$ da biomassa microbiana ruminal nos animais que recebem dietas ricas em fibras e estão envolvidos na solubilização da parede celular lignificada (Oliveira et al., 2007). Animais adultos e que ingerem maiores proporções de fibras vegetais possuem maior população fúngica no rúmen, sendo que a principal espécie encontrada em bovinos é Neocallimastix variabilis, seguido pela Anaeromyces elegans que também é encontrada no trato digestório desses animais, sendo responsáveis pela degradação da parte lignificada da parede celular das forragens. Essa capacidade de ação sobre a parede vegetal das forragens diminui a rigidez estrutural, aumentando a superfície de aderência para as bactérias (Fondevila et al., 1998).

A transmissão de fungos entre os ruminantes pode ser via saliva ou ar, ou quando estão aderidos às partículas de alimentos que serão ingeridos (Theodorou et al., 1996) e, ao chegar ao rúmen, permanece na fase líquida até aderir e começar a degradação da parede vegetal do alimento, sendo o crescimento do seu micélio estritamente ligado ao substrato (Onoda et al., 1996).

\section{Os bacteriófagos do rúmen}

Os bacteriófagos são vírus que infectam bactérias e são presentes no rúmen em grande quantidade (Kamra, 2005). Esses vírus se aderem à bactéria, perfuram sua parede celular e injetam na célula hospedeira o seu conteúdo genético, sendo que o número de partículas virais encontradas ultrapassa o número de células bacterianas em instantes após alimentação (Church, 1974).

Os bacteriófagos são considerados patógenos obrigatórios e específicos para diferentes bactérias presentes no rúmen. Entretanto, estes patógenos ajudam no turnover da massa bacteriana no rúmen, por disponibilizar, pela a lise, proteína bacteriana como fonte de aminoácidos para o animal (Kamra, 2005).

Um estudo mais recente de metagenômica viral do rúmen de bovinos identificou mais de 28.000 genótipos virais diferentes, sendo a grande maioria das partículas sequenciadas (aproximadamente 78\%) pertencentes a vírus ainda não descritos (Gilbert et al., 2020).

\section{Considerações finais}

Tendo em vista a técnica descrita e os resultados apresentados pela literatura científica citada, desde que a técnica operatória atenda as exigências e certificação do Comitê de Ética na Utilização de Animais na experimentação científica, torna-se uma prática importante para as pesquisas na área de nutrição de ruminantes e em casos indispensáveis de necessidades de realizar a transfaunação, além da possibilidade de estudos mais aprofundados da microbiota ruminal e sua complexidade.

\section{Referências bibliográficas}

Arcuri, P. B., Lopes, F. C. F., \& Carneiro, J. (2011). Microbiologia do rumen. In T. T. Berchielli, A. V Pires, \& S. G. Oliveira (Eds.), Nutrição de Ruminantes (Issue 2th ed., pp. 115-148). FUNEP.

Atasoy, N., \& Taş, A. (2003). Considerations for gastrointestinal cannulation (rumen, duodenum and ileum) in sheep with a ruminal, a simple t-type and a modified t-type cannula. Deutsche Tierarztliche Wochenschrift, 110(7), 299-302.

BRASIL, Lei número 11.794, de 8 de outubro de 2008. Brasília, Casa Civil, 2008.

Cabrera, R., López, A., Maiztegui, J., \& Marín, M. P. (1996). Fistulación y canulación permanente del comportamiento 1 (rumen) en alpacas (lama pacos). Avances En Ciencias Veterinarias, 11(2), 108111. https://doi.org/10.5354/0716-260x.1996.4780.

Church, D. C. D. C. (1974). Fisiología digestiva y nutrición de los rumiantes. Acribia.

Coalho, M. R., Nogueira Filho, J. C. M., Cunha, J. A., \& Lima, C. G. (2003). Estudo dos protozoários ciliados em bovinos consumindo dietas com diferentes níveis de proteína não degradável no rúmen 1. Acta Scientiarum. Animal Sciences, 25(1), 193-199. https://doi.org/10.4025/actascianimsci.v25i1.2146.

Dehority, B. A. (2003). Rumen microbiology. University Press. 
DePeters, E. J., \& George, L. W. (2014). Rumen transfaunation. Immunology Letters, 162(2), 69-76. https://doi.org/10.1016/j.imlet.2014.05.009.

Duffield, T., Plaizier, J. C., Fairfield, A., Bagg, R., Vessie, G., Dick, P., Wilson, J., Aramini, J., \& McBride, B. (2004). Comparison of techniques for measurement of rumen $\mathrm{pH}$ in lactating dairy cows. Journal of Dairy Science, 87(1), 59-66. https://doi.org/http://dx.doi.org/10.3168/jds.S00220302(04)73142-2

Fondevila, M., Muñoz, G., Castrillo, C., Vicente, F., \& Martín, S. M. (1998). Procesos implicados en la digestión microbiana de los forrajes de baja calidad. Revista de La Facultad de Agronomía, 15(1), 11.

Fonty, G., Jouany, J. P., Forano, E., \& Gouet, P. (1995). L'écosystème microbien du réticulo-rumen. Nutrition Des Ruminants Domestiques, 8(1), 299-347.

Fouts, D. E., Szpakowski, S., Purushe, J., Torralba, M., Waterman, R. C., MacNeil, M. D., Alexander, L. J., \& Nelson, K. E. (2012). Next generation sequencing to define prokaryotic and fungal diversity in the bovine rumen. PloS One, 7(11), e48289. https://doi.org/10.1371/journal.pone.0048289.

Gilbert, R. A., Townsend, E. M., Crew, K. S., Hitch, T. C. A., Friedersdorff, J. C. A., Creevey, C. J., Pope, P. B., Ouwerkerk, D., \& Jameson, E. (2020). Rumen virus populations: technological advances enhancing current understanding. Frontiers in Microbiology, 11, 450. https://doi.org/10.3389/fmicb.2020.00450.

Godwin, I. R., \& Chaffey, G. A. (1988). Simple rapid method of rumen cannulation. Australian Veterinary Journal, 65(7), 227. https://doi.org/10.1111/j.1751-0813.1988.tb14467.x.

Grovum, W. L. (1989). An improved rumen cannulation technique to minimize leakage. Acta Veterinaria Scandinavica, 86, 225-228.

Henderson, A. (2016). Why Do These cows have holes drilled into their sides?. PETA - People for ethical treatment of animals, $\left[\begin{array}{lllll}S . & l .\end{array}\right]$ p. 1-1, 26 maio. Disponível em: https://www.peta.org/blog/fistulated-cannulated-cows/. Acesso em: 2 mar. 2021.

Hobson, P. N., \& Stewart, C. S. (2012). Rumen microbial ecosystem (2nd ed.). Blackie Academic \& Professional.

Hook, S. E., Wright, A. D. G., \& McBride, B. W. (2010). Methanogens: methane producers of the rumen and mitigation strategies. Archaea, 2010(Article ID 945785), 11.

Horigane, A., Gochou, S., Kishi, F., Ohtomo, Y., \& Horiguchi, M. (1989). Silicone rumen cannula with a soft cylindrical part and a hard flange. Journal of Dairy Science, 72(12), 3230-3232. https://doi.org/10.3168/jds.S0022-0302(89)79481-9.

Hungate, R. E. (1966). The Rumen and its microbes. In The rumen and its microbes (Academic P). https://doi.org/10.1016/B978-1-4832-3308-6.50005-X

Ivan, M., Neill, L., Forster, R., Alimon, R., Rode, L. M., \& Entz, T. (2000). Effects of Isotricha, Dasytricha, Entodinium, and total fauna on ruminal fermentation and duodenal flow in wethers fed different diets. Journal of Dairy Science, 83(4), 776-787. https://doi.org/10.3168/jds.S00220302(00)74940-X.

Kamra, D. N. (2005). Rumen microbial ecosystem. Current Science, 89(1), 124-135.

Komarek, R. J. (1981). Rumen and abomasal cannulation of sheep with specially designed cannulas and a cannula insertion instrument. Journal of Animal Science, 53(3), 790-795. https://doi.org/10.2527/jas1981.533790x.

Kozloski, G. V. (2011). Bioquímica dos ruminantes (3a Ed., Vol. 1). Editora Universidade Federal de Santa Maria.

Krause, D. O., \& Russell, J. B. (1996). How many ruminal bacteria are there? Journal of Dairy Science, 79(8), 1467-1475.

Laflin, S. L., \& Gnad, D. P. (2008). Rumen Cannulation: Procedure and Use of a Cannulated Bovine. Veterinary Clinics of North America: Food Animal Practice, 24(2), 335-340. https://doi.org/http://dx.doi.org/10.1016/j.cvfa.2008.02.007

Martin, C., Morgavi, D. P., \& Doreau, M. (2010). Methane mitigation in ruminants: from microbe to the farm scale. Animal, 4(03), 351-365. https://doi.org/10.1017/S1751731109990620. 
McAllister, K. A., Lennon, F., Bowles-Biesecker, B., McKinnon, W. C., Helmbold, E. A., Markel, D. S., Jackson, C. E., Guttmacher, A. E., Pericak-Vance, M. A., \& Marchuk, D. A. (1994). Genetic heterogeneity in hereditary haemorrhagic telangiectasia: possible correlation with clinical phenotype. Journal of Medical Genetics, 31(12), 927-932.

Mogha, I. V, \& Bhargava, A. K. (1979). Rumen fistula technique and utility. Indian Veterinary Journal, 56(10), 885-887.

Mosoni, P., Martin, C., Forano, E., \& Morgavi, D. P. (2011). Long-term defaunation increases the abundance of cellulolytic ruminococci and methanogens but does not affect the bacterial and methanogen diversity in the rumen of sheep. Journal of Animal Science, 89(3), 783-791.

Muniz, J. A., Savian, T. V., \& Scalon, J. D. (2008). Parameters estimation in the model for in situ degradability of mertens and loften. Ciência e Agrotecnologia, 32, 1622-1628. https://doi.org/10.1590/s1413-70542008000500040.

Muzzi, L. A. L., Muzzi, R. A. L., \& Gabellini, E. L. A. (2009). Técnica de fistulação e canulação do rúmen em bovinos e ovinos. Ciência Agrotécnica, 33, 2059-2064.

Nagaraja, T. G., Newbold, C. J., Van Nevel, C. J., \& Demeyer, D. I. (2012). Manipulation of ruminal fermentation. In P. N. Hobson \& C. S. Stewart (Eds.), The rumen microbial ecosystem (Vol. 1, pp. 523-632). Black Acaddemic \& Professional.

Oliveira, J. S., Zanine, A. M., \& Santos, E. M. (2007). Fisiologia, manejo e alimentação de bezerros de corte. Arquivos de Ciências Veterinárias e Zoologia da UNIPAR, 10(1), 39-48.

Onoda, A., Kobayashi, Y., \& Hoshino, S. (1996). Effects of amino acids on the growth of an anaerobic rumen fungus Neocallimastix sp N 13. Reproduction Nutrition Development, 36(3), 311-320.

Pereira, J. C., Almeida, M. S., Cecon, P. R., \& Queiroz, A. C. (2002). Dinâmica da degradação ruminal por novilhos mantidos em pastagem natural, em diferentes épocas do ano. Revista Brasileira de Zootecnia, 31, 740-748.

Piknová, M., Javorský, P., Guczynska, W., Kasperowicz, A., Michalowski, T., \& Pristaš, P. (2006). New species of rumen treponemes. Folia Microbiologica, 51(4), 303-305. https://doi.org/10.1007/BF02931819.

Santos, J. E. P. (2011). Distúrbios metabólicos. In T. T. Berchielli, A. V Pires, \& S. G. Oliveira (Eds.), Nutrição de Ruminantes (Vol. 1, Issue 2th ed., pp. 439-520). FUNEP.

Santra, A., \& Karim, S. A. (2002). Rumen cannulation in sheep and goats: Fabrication of cannula and surgical procedure for its implantation. Indian Journal of Animal Sciences, 72(11), 978-980.

Schalk, A. F. \& Amadon, R.S. (1928). Physiology of the ruminant stomach (bovine): study of the dynamic factors. North Dakota agricultural Experiment. Station Bulletin. 276:15-50

Siqueira, F., \& Caviglioni, M. (2021). Metagenômica, nanotecnologia e nutrição animal: alternativas para o uso de antibióticos e mitigação de gases de efeito estufa. In Embrapa Gado de Corte (Vol. 283). Embrapa Gado de Corte.

Theodorou, M. K., Mennim, G., Davies, D. R., Zhu, W.-Y., Trinci, A. P. J., \& Brookman, J. L. (1996). Anaerobic fungi in the digestive tract of mammalian herbivores and their potential for exploitation. Proceedings of the Nutrition Society, 55(3), 913-926.

Thyfault, H. A., Leffel, E. C., \& Der Huang, M. (1975). Simplified method for producing permanent ruminal fistulae. Journal of Dairy Science, 58(12), 1899-1901. https://doi.org/10.3168/jds.S00220302(75)84805-3.

Welkie, D. G., Stevenson, D. M., \& Weimer, P. J. (2010). ARISA analysis of ruminal bacterial community dynamics in lactating dairy cows during the feeding cycle. Anaerobe, 16(2), 94-100.

Williams, A. G. (1986). Rumen holotrich ciliate protozoa. Microbiological Reviews, 50(1), 25-49.

Withers, P. C. (1992). Comparative animal physiology. Saunders College Pub. Philadelphia.

Histórico do artigo:

Recebido: 15 de outubro de 2021

Aprovado: 15 de novembro de 2021

Disponível online: 02 de março de 2022
Licenciamento: Este artigo é publicado na modalidade Acesso Aberto sob a licença Creative Commons Atribuição 4.0 (CC-BY 4.0), a qual permite uso irrestrito, distribuição, reprodução em qualquer meio, desde que o autor e a fonte sejam devidamente creditados. 